\title{
ACADEMIC ACHIEVEMENT OF HIGH SCHOOL STUDENTS IN RELATION TO THEIR EMOTIONAL STABILITY
}

\author{
Assistant Professor, PhD, Sima Kalita, \\ Department of Education, Gauhati University \\ Assam, India \\ simakalita_gu@rediffmail.com
}

Original Scientific Paper

doi:10.5937/jouproman4-11932

\begin{abstract}
In the present study an attempt was made to know the relationship between personality factor emotional stability and academic achievement of the high school students of South Kamrup district of Assam, India. Students were randomly selected from different high schools of the selected area. A sample of 400(both boys and girls) students was selected and Cattell's Jr. High School Personality Questionnaire (HSPQ) was administered to them and record of academic achievement was collected from the school record. Subsequently the data were subjected to statistical analysis with the help of percentage analysis and $\mathrm{x}^{2}$. Results indicated a significant relationship between emotional stability and academic achievement of high school students of South kamrup district, Assam, India. The study also depicted that high level of emotional stability leads to high academic achievement and low emotional stability leads to low level of academic achievement.
\end{abstract}

Key words: Emotional Stability, Academic achievement, High school Students, South Kamrup District.

\section{Introduction}

Human beings are constantly striving for adjustment with the environment. In this process the behaviour, attitude and activity of an individual is influenced by different factors. Modern scientific and technological advancements have influenced the mindset and behavioral dimension of the people tremendously. Again many personality traits and psychological factors like dependency, independency, persistency, consistency, drive, incentive, frustration, consistent striving for achieving the goal have remarkable influence on behaviour and activity of the people. These influences may be positive as well as negative. Like many other important factors personality factors can also bring success or failure to a student. Among different topics of psychology more fascinating one is personality (Kalita, S (2013)).

Many psychologists, philosophers have defined personality in different ways. Most of the early definitions of personality emphasized the expressive aspects of personality. Woodworth (1921), for example, defined personality, as the 'quality' of the individuals' total behaviour. Psychologists of the later part have given stress on the mode of adjustment as the determinant of personality.

Kemph (1919) has defined personality as 'The habitual mode of adjustment which the organism effect between its own egocentric drives and the exigencies of the environment.' Some psychologists try to view personality as stimulus and some other as the response. Now gradually the term personality is meant that it is the organization and integration of total human traits. Cattell and Eysenck's theories identify specific personality orientations which they have termed as a mosaic for behaviour, through their trait theories. Allport was the initiator of the trait theory who found 4,504 descriptive personality terms. Cattell then reduced these terms to 171 by eliminating the synonymous. Then he discovered 16 key traits forming the $16 \mathrm{PF}$ or 16 personality factors. He then prepared $16 \mathrm{PF}$ questionnaire and also $14 \mathrm{PF}$ questionnaire meant for the high school students. 
The Personality Factors included in the $14 \mathrm{PF}$ questionnaire are Factor $\mathrm{A}$ (Warmth), B (Intelligence), C (Emotional stability), D(Activeness), E (Dominance), F (Liveliness), G(Rule-conscious), $\quad \mathrm{H}$ (Social Boldness), I (Sensitivity), J (Zestfulness), O (Apprehension) Q2 (Self Reliance), Q3 (Perfectionism) and Q4 (Tension). Though in the High school personality Questionnaire of Cattell 14PF are included, for the present study only Factor C or Emotional Stability has been considered. These different traits affect individuals positively or negatively and in this way also determine the achievement level of individuals. Emotionality is the observable behaviour and physiological component of emotion. It is a measure of person's emotional reactivity to a stimulus (Reber, A. S. \& Reber E (2001)). Emotional stability is the person's ability to remain stable that is calm in the face of adverse situations.

Here in this study an attempt was made to see the relationship between Emotional stability and Academic achievement of the High school students of South Kamrup district, Assam, India.

\section{Operational Definitions of the Key words}

\section{(a) High school Students:}

The students studying in $\mathrm{ix}^{\text {th }}$ and $\mathrm{x}^{\text {th }}$ standards in different High Schools in the study area, of both sexes had been considered as High School Students.

\section{(b) Emotional Stability:}

Emotional stability or Personality factor C as measured by Cattell's Jr. High school Personality Questionnaire was regarded as emotional stability for the present study. Two dimensions, namely high and low emotional stability had been taken into consideration here.

\section{(c) Academic achievement:}

The marks obtained by the students in annual examination had been considered as the academic achievement of the students. Academic achievement had been categorized as High, Above Average, Average, Below average and Low with the help of percentile point.

\section{(d) South Kamrup District:}

The South Kamrup district comprises of Chhaygaon, Palasbari and Boko legislative assembly constituencies. It is in the state of Assam in the North east corner of India. It is known for natural beauty and emotional integrity among people from different castes, religions and ethnic groups. The Chaygaon revenue circle office is functioning as the office of the Deputy Commissioner of the district. Six complete blocks namely Boko block, Chamaria Block, Chaygaon Block, Bongaon Block, Goroimari Block, Rampur Block, Chayani Block and parts of Rani Block are included within the jurisdiction District.

\section{Need and Significance of the Study}

Personality traits have a great role to play in the activity and behaviour of an individual. Emotional stability is a trait which can lead the individual's behavioural dimensions either in positive or in negative direction. This particular trait can influence the academic activities of the students and ultimately the academic achievement. To guide the students in the right direction it is imperative to know their emotional stability and how this factor has influenced their achievement in academic arena. Again educational policies are based on some investigations. Such type of study is necessary for helping the policy planners, parents, teachers and the administrators to plan and execute their policies. 


\section{Objective of the Study}

(a) To find out the relationship between Emotional stability and academic achievement of the High school students.

\section{Hypothesis of the Study}

$\mathbf{H}_{\mathbf{0 1}}$ : Emotional stability and Academic achievement of High school students are unrelated.

\section{Variables taken for the study}

Independent Variable: Emotional Stability or Personality Factor C.

Dependent Variable: Academic achievement of the High school students.

\section{Methodology}

\section{(a) Method}

Descriptive Survey method had been applied to know the status of academic achievement of the students in relation to their emotional stability.

(b) Population and Sample

The population of the present study comprised of all the High school students of South Kamrup district of Assam, India. However the sample strength of the study had been confirmed to 400 High School students, both boys and girls.

\section{(c) Sampling technique}

Simple random sampling technique had been used for sample selection. Lottery method of random sampling technique was followed in the present study.

\section{(d) Tools Used}

(i) Cattell's Jr. High School Personality Questionnaire (HSPQ) was used to gather data regarding emotional behaviour of the students. In the questionnaire two dimensions namely High and Low were included.
High Factor $\mathbf{C}$ means emotionally stable, mature, having higher ego strength

Low factor $\mathbf{C}$ means easily affected by feelings, emotionally less stable

(ii) Data regarding academic achievement of the students collected from the school record.

\section{(e) Statistics used for Analysis of Data}

(i) Percentage analysis

(ii) Chi-square test

\section{Analysis, Interpretations and Findings}

This part of the paper deals with the analysis, interpretations and findings of the investigations. The collected data were analyzed with the help of percentage analysis and chi-square test. The analysis has been presented below.

Table 1: Academic achievement of High School students according to Emotional stability

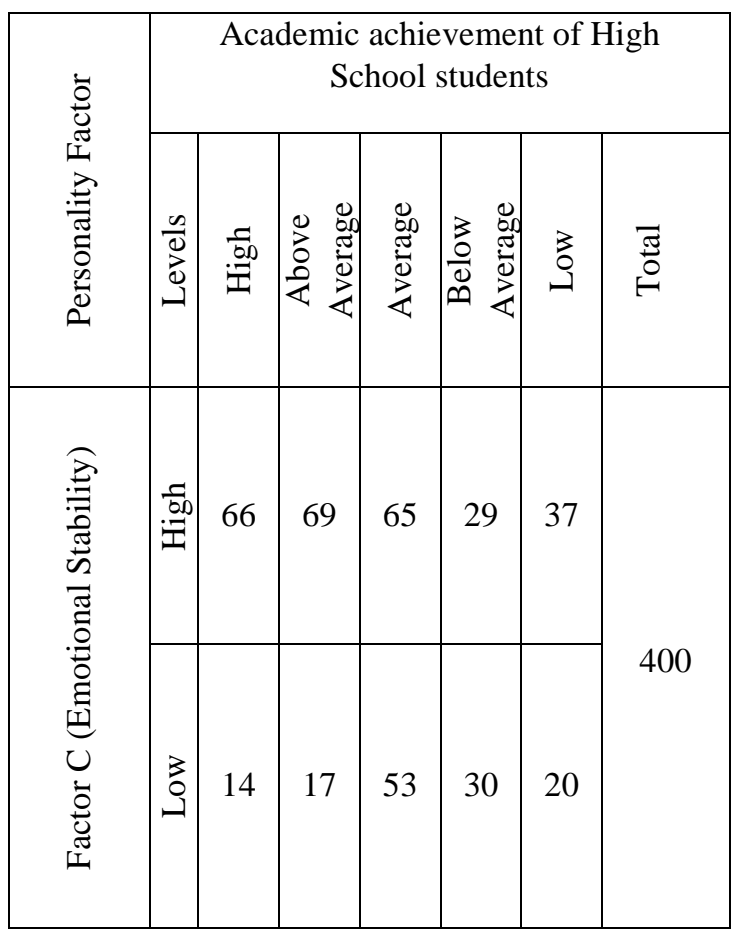


Table-1 shows the concentration of academic achievement according to personality factor $\mathrm{C}$ or Emotional stability. Above table depicts that high factor $\mathrm{C}$ or high emotional stability leads to concentration of more students in High, Above Average and Average categories of academic achievement.

Table 2: $\mathrm{X}^{2}$ showing the relationship between Emotional stability and

Academic achievement

\begin{tabular}{|c|c|c|c|c|}
\hline Variable & $\mathbf{N}$ & $\mathrm{df}$ & $\mathrm{X}^{2}$ & $\begin{array}{c}\text { Level of } \\
\text { significan } \\
\text { ce }\end{array}$ \\
\hline 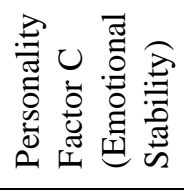 & \multirow[t]{2}{*}{400} & \multirow[t]{2}{*}{4} & \multirow[t]{2}{*}{$54.15^{* *}$} & \multirow[t]{2}{*}{0.01} \\
\hline 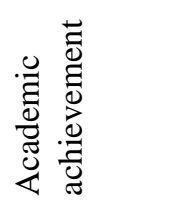 & & & & \\
\hline
\end{tabular}

Table-2 depicts that $\mathrm{X}^{2}$ value showing the relationship between personality factor $\mathrm{C}$ or Emotional stability and Academic achievement is significant at 0.01 level for 4 degrees of freedom. This leads to rejection of $\mathrm{H}_{\mathrm{o} 1}$. It indicates that Emotional stability and Academic achievement are associated significantly and hence not independent of each other.

\section{Findings}

From the present study it is clear that majority $(66.5 \%)$ of the students had high personality factor $\mathrm{C}$ or High emotional stability.

Regarding the relationship between personality factor Emotional stability or personality factor $\mathrm{C}$ and academic achievement, it was found that they were associated significantly. Descriptive statistics (Ref. Table 1) also shows that those High School students who are easily affected by feelings, emotionally less stable (low factor C) are leaning more towards the lower side of Academic achievement and majority of students who are emotionally stable, mature, having higher ego strength (high factor C) are more oriented towards High, Above Average and Average category of Academic achievement.

\section{Conclusions}

From the study it can be concluded that personality factor Emotional stability is a significant factor in academic achievement. Therefore in the school and also in the home teachers and parents should be aware of the emotionality of the students. They should try to create congenial atmosphere so that the students become emotionally stable. Apart from that in the school premises measures should be taken to identify the emotionally less stable students and to provide them appropriate counseling. It is hoped that this paper will contribute to the field of the study of emotional stability and academic achievement and encourage the parents, teachers, policy planners and all concerned to make every students a real asset for the society.

\section{References}

1. Kalita, S.(2013) 'The role of Personality factors and Parental encouragement in developing Achievement motivation in High school students of greater Guwahati'. Ph.D. Thesis, Gauhati University, Guwahati, Assam.

2. Woodworth, R.S.(1921). Psychology: A study of Mental Life, New York, H. Holt.

3. Munn, as cited in Mital,S.S.(2006) . Child development of Personality Traits(p. 15). Delhi, Kalpaz Publications.

4. Reber, A. S. \& Reber E,(2001). The penguin Dictionary of psychology, Penguine Books, ISBN 0-14-05451-1 